\title{
Influência de diferentes fontes e níveis de fibra na dieta de juvenis de pacu (Piaractus mesopotamicus) sobre o desempenho zootécnico, parâmetros somáticos e composição centesimal
}

\author{
Influence of different sources and fiber levels in the diet of juvenile pacu (Piaractus \\ mesopotamicus) on the growth performance, somatic parameters and proximate \\ composition
}

\begin{abstract}
Bruno da Silva Pires ${ }^{1 *(O R C I D ~ 0000-0002-1250-9854)}$, Alexandra Pretto 2 (ORCID 0000-0002-5874-9108), Cristiano Miguel Stefanello 2 (ORCID 0000-0002-3977-3700), Pâmela Tasca de Carvalho ${ }^{2}$, Fabio de Araújo Pedron 2 (ORCID 0000-00032869-7850)
\end{abstract}

1Universidade Estadual de Maringá, Maringá, PR, Brasil. Autor para correspondência: brunodsp.2013@gmail.com
2Universidade Federal do Pampa, Uruguaiana, RS, Brasil.

Submissão: 21/05/2021 / Aceite: 14/10/2021

\begin{abstract}
RESUMO
O objetivo do presente trabalho foi avaliar os efeitos da casca de soja e da casca de arroz sobre o desempenho zootécnico, parâmetros somáticos e composição centesimal dos peixes inteiros de juvenis de pacu (Piaractus mesopotamicus). Para isso, foram utilizados 216 juvenis de pacu, com peso médio de $6 \pm 0,81$ gramas, distribuídos em 18 caixas d'água, em sistema de recirculação. Foram formuladas seis dietas contendo os níveis de 10, 13 e 15\% de inclusão de FDN para cada fonte de fibra, com $30 \%$ de proteína bruta e $3.000 \mathrm{Kcal} \mathrm{Kg}^{-1}$ de energia digestível. Foi observado que os níveis de 10 e $13 \%$ de FDN promoveram os melhores resultados para as variáveis de desempenho como peso final, ganho em peso, taxa de crescimento específico e comprimento final. Também foi possível observar que os peixes alimentados com a dieta contendo $10 \%$ de FDN apresentaram um maior rendimento de carcaça, porém não foi observada diferença entre os índices, digestivo somático, hepatossomático e quociente intestinal. Já, para as variáveis de composição centesimal dos peixes inteiros, não foram observadas diferenças significativas. Sendo assim, pode-se concluir que até $13 \%$ de FDN não prejudica o desempenho zootécnico, qualidade de carcaça e os parâmetros somáticos dos peixes.
\end{abstract}

PALAVRAS-CHAVE: Coprodutos, casca de soja, casca de arroz, desempenho zootécnico, fibra em detergente neutro.

\begin{abstract}
The objective of the present work was to evaluate the effects of soybean husk and rice husk on the performance, somatic parameters and proximate composition of whole fish of juvenile pacu (Piaractus mesopotamicus). For this, 216 juveniles of pacu were used, with an average weight of $6 \pm$ 0.81 grams, distributed in 18 water tanks, in a recirculation system. Six diets were formulated containing levels of 10,13 and $15 \%$ of NDF inclusion for each fiber source, with $30 \%$ of crude protein and $3,000 \mathrm{Kcal} \mathrm{Kg}^{-1}$ of digestible energy. It was observed that the levels of 10 and $13 \%$ of NDF promoted the best results for performance variables such as final weight, weight gain, specific growth rate and final length. It was also possible to observe that fish fed a diet containing $10 \%$ NDF had a higher carcass yield, but no difference was observed between the somatic, hepatosomatic and intestinal quotient digestive indexes. However, no significant differences were observed for the proximate composition variables of whole fish. Thus, it can be concluded that up to $13 \%$ of NDF does not affect the zootechnical performance, carcass quality, and somatic parameters of the fish.
\end{abstract}

KEYWORDS: Co-products, soy husk, rice husk, neutral detergent fiber, zootechnical performance. 


\section{INTRODUÇÃO}

A fibra é composta por polissacarídeos não amiláceos insolúveis e oligossacarídeos resistentes à digestão enzimática no trato gastrointestinal (MONTAGNE et al. 2003). As fibras podem ser classificadas como insolúvel, composta por celulose, hemicelulose insolúvel e lignina e solúvel, que inclui pectina, gomas e mucilagens (GOULART et al. 2018). A fibra solúvel reduz a velocidade de absorção de nutrientes, no trato gastrointestinal, devido seu efeito fisiológico, que aumenta o tempo de trânsito do bolo intestinal. Já a fibra insolúvel dos alimentos acelera o trânsito gastrointestinal e contribui com o aumento de absorção de água (FABREGAT et al. 2011a). Como as fibras não são digeridas no intestino, chegam intactas ao cólon e podem servir de substrato para o desenvolvimento de bactérias fermentativas, com liberação de energia através dos ácidos graxos de cadeia curta, melhorando a morfologia das células intestinais, além de impedir o desenvolvimento de bactérias patogênicas (GOULART et al. 2018).

As fibras apresentam diferentes efeitos no organismo dos peixes, dependendo de sua fonte ou nível de inclusão. GOULART et al. (2018) observaram que juvenis de jundiá (Rhamdia quelen) alimentados com mucilagem, pectina ou $\beta$-glucana mais manana em níveis de 0,5 ou $1 \%$ de inclusão, apresentaram melhores respostas para o perfil bioquímico e imunológico após manejo de estresse nos peixes. Já MIRGHAED et al. (2018) avaliaram os efeitos da fibra fermentada, probiótico comercial ou a combinação destes dois aditivos na dieta de juvenis de Rutilus frisii kutum e observaram que estes aditivos, separados ou em conjunto, melhoram o desempenho zootécnico, o sistema imune e aumentam a microbiota intestinal autóctone dos peixes.

O pacu é uma espécie endêmica das bacias dos rios Paraná, Paraguai e Uruguai e amplamente distribuído nas planícies alagadas do pantanal (URBINATI et al. 2010). Esta espécie nativa tem grande potencial de cultivo, sendo que no ano de 2018, a produção nacional atingiu 11.570 toneladas (IBGE 2019). Devido ao seu hábito alimentar onívoro, apresenta menor exigência nutricional em termos de proteína e aminoácidos e aceita maiores teores de carboidratos não estruturais (amido) na dieta, comparado com outras espécies (URBINATI et al. 2010, BOSCOLO et al. 2011).

Estudos sobre os efeitos de diferentes fontes de fibra na dieta do pacu já foram realizados, no entanto, pouco se sabe sobre o efeito da casca de soja sobre a nutrição desta espécie. FABREGAT et al. (2011a) observaram que a casca de soja retardou o tempo de trânsito gastrintestinal e diminuiu a absorção e utilização da proteína e energia bruta das dietas. Em outro trabalho com a espécie, os autores avaliaram os efeitos da casca de soja sobre os parâmetros de desempenho, composição bromatológica e histologia do fígado, e observaram diminuição no desempenho dos juvenis, porém não foi observado efeito sobre os parâmetros bromatológicos e na histologia do intestino (FABREGAT et al. 2011b). Nestes dois estudos foi utilizado o nível de $26,4 \%$ de inclusão da casca de soja na dieta, superior aos níveis avaliados no presente estudo. Já, em relação à casca de arroz, não há nenhum estudo sobre os efeitos deste coproduto na alimentação da espécie.

Neste sentido, o objetivo deste estudo foi avaliar os efeitos de diferentes níveis de fibra $(10 ; 13$ ou $15 \%$ ) proveniente de coprodutos agroindustriais como a casca de arroz e a casca de soja em dietas para o pacu, através da análise de parâmetros de desempenho zootécnico, índices somáticos e composição centesimal dos peixes inteiros.

\section{MATERIAL E MÉTODOS}

O experimento foi realizado no Laboratório Experimental de Piscicultura da Universidade Federal do Pampa (UNIPAMPA), Campus Uruguaiana, de abril a junho de 2016. Foram utilizados 216 juvenis de pacu com peso médio inicial de $6 \pm 0,81$ gramas, mantidos em sistema de recirculação de água, com biofiltro e aquecimento, e distribuídos em 18 unidades experimentais com capacidade de 40 litros cada uma. Foram alocados 12 peixes por tanque. O ensaio de alimentação teve duração de 60 dias, sendo realizadas biometrias quinzenais para avaliar o desempenho zootécnico e ajustar o fornecimento da ração. Previamente às pesagens, os peixes eram mantidos em jejum durante 24 horas e a biomassa de cada tanque era registrada. A oferta de ração ( $3 \%$ do peso vivo por unidade experimental) foi dividida em duas alimentações diárias, fornecida às 8:30 e às 15:30 horas. Uma hora após a alimentação da manhã, as caixas eram sifonadas para a retirada dos resíduos e troca de parte de água ( $5 \%$ do volume total).

As seis rações experimentais foram preparadas a partir da inclusão das diferentes fontes de fibra, a casca de arroz e a casca de soja. A casca de arroz foi incluída nos níveis de 4, 8 ou $12 \%$ e a casca de soja foi adicionada aos níveis de 5, 10 ou 15\%. Assim, os teores de fibra em detergente neutro em cada dieta atingiram valores próximos a 10,13 ou $15 \%$. As dietas foram formuladas para conter aproximadamente $30 \%$ de proteína bruta e $3.000 \mathrm{Kcal} \mathrm{Kg}^{-1}$ de energia digestível (Tabela 1), utilizando tabela de composição de 
ingredientes (ROSTAGNO et al. 2005). As rações foram preparadas utilizando a farinha de carne e os farelos vegetais, as fontes de fibra e demais ingredientes, que foram pesados e misturados manualmente, com posterior inclusão do óleo e água, e após a homogeneização da mistura, as dietas foram peletizadas em moedor de carne. Após a peletização, as dietas foram secas em estufa de circulação de ar forçado a 50 ${ }^{\circ} \mathrm{C}$ durante 24 horas e mantidas refrigeradas até serem fornecidas aos peixes.

Tabela 1. Formulação e Composição calculada das dietas experimentais (expressas em \%). Table 1. Formulation and composition calculated from experimental diets (expressed in \%).

\begin{tabular}{lcccccc}
\hline \multirow{2}{*}{ Ingredientes } & \multicolumn{3}{c}{ Casca de soja } & \multicolumn{3}{c}{ Casca de arroz } \\
\cline { 2 - 6 } & $5 \%$ & $10 \%$ & $15 \%$ & $4 \%$ & $8 \%$ & $12 \%$ \\
\hline Farelo de soja & 35,0 & 34,0 & 34,0 & 35,0 & 36,0 & 36,0 \\
Farinha de carne & 29,0 & 29,0 & 29,0 & 30,0 & 30,0 & 30,0 \\
Milho & 14,0 & 13,0 & 7,0 & 15,0 & 12,0 & 7,0 \\
Farelo de arroz desengordurado & 7,0 & 5,0 & 7,0 & 7,0 & 5,0 & 6,0 \\
Casca de soja & 5,0 & 10,0 & 15,0 & - & - & - \\
Casca de arroz & - & - & - & 4,0 & 8,0 & 12,0 \\
Óleo & 2,0 & 3,0 & 4,0 & 2,0 & 3,0 & 4,0 \\
Premix vitamínico e mineral ${ }^{1}$ & 3,0 & 3,0 & 3,0 & 3,0 & 3,0 & 3,0 \\
Sal & 1,0 & 1,0 & 1,0 & 1,0 & 1,0 & 1,0 \\
Material inerte (areia) & 4,0 & 2,0 & - & 3,0 & 2,0 & 1,0 \\
\hline$\quad$ Composição Centesimal & & & & & & \\
PB $^{2}$ & 33,27 & 33,13 & 33,53 & 33,29 & 33,31 & 33,10 \\
ED $^{3}$ & 3025,02 & 3034,71 & 3062,26 & 3064,18 & 3036,98 & 3027,12 \\
EE $^{2}$ & 9,53 & 10,27 & 11,41 & 9,68 & 10,31 & 11,26 \\
FDN $^{2}$ & 10,89 & 13,05 & 15,65 & 10,95 & 13,12 & 15,57 \\
AMIDOyyyyy$^{2}$ & 17,49 & 15,57 & 12,15 & 18,40 & 15,33 & 12,28 \\
MM $^{2}$ & 9,74 & 9,49 & 9,60 & 10,95 & 11,75 & 12,74 \\
Ca $^{2}$ & 26,95 & 26,26 & 24,16 & 27,65 & 26,94 & 25,19 \\
P $^{2}$ & 22,76 & 22,17 & 20,37 & 23,35 & 22,74 & 21,24 \\
Ca:P & 1,18 & 1,18 & 1,19 & 1,18 & 1,18 & 1,19
\end{tabular}

PB: Proteína Bruta; ED: Energia Digestível; EE: Extrato Etéreo; FDN: Fibra em Detergente Neutro; MM: Matéria Mineral; Ca: Cálcio; P: Fósforo; Ca:P: Relação Cálcio e Fósforo; ${ }^{1}$ Composição do suplemento vitamínico-mineral por Kg de produto: ác. Fólico: $250 \mathrm{mg}$; ác. Pantotênico: $5000 \mathrm{mg}$; antioxidante: 0,06 g; biotina: $125 \mathrm{mg}$; cobalto: $25 \mathrm{mg}$; cobre: 2000 mg; ferro: $820 \mathrm{mg}$; iodo: $100 \mathrm{mg}$; manganês: $3750 \mathrm{mg}$; niacina: $5000 \mathrm{mg}$; selênio: $75 \mathrm{mg}$; vit. A: $1000000 \mathrm{UI}$; vit. B1: 1250 mg; vit. B2: 2500 mg; vit. B6: 2485 mg; vit. B12: 3750 mg; vit. C: 28000 mg; vit. D3: 500000 UI; vit. E: 20000UI; vit. $5000 \mathrm{mg}$; zinco: $1750 \mathrm{mg}$. ${ }^{2}$ Composição calculada (ROSTAGNO et al. 2005). ${ }^{3} \mathrm{Calculada}\left(\mathrm{Kcal}_{\mathrm{Kg}}{ }^{-1}\right)$ a partir da fórmula: (Proteína bruta*5,64*0,83) + (Extrato etéreo*9,44*0,88) + (amido*4,11*0,65))*10 (MEYER et al. 2004).

O delineamento experimental utilizado no estudo foi o inteiramente casualizado em esquema fatorial 2 (fontes de fibra - casca de arroz e casca de soja) x 3 (níveis de FDN - 10, 13 e 15\%) totalizando seis tratamentos com três repetições cada.

Os parâmetros de qualidade de água como oxigênio dissolvido e temperatura foram mensurados pela manhã e à tarde, utilizando oxímetro digital (POLITERM POL 60) e termômetro de coluna de mercúrio. Foram obtidos os seguintes valores médios: $6,20 \pm 1,69 \mathrm{mg} \mathrm{L}^{-1}$ e $25,35 \pm 2,44{ }^{\circ} \mathrm{C}$. Os parâmetros como $\mathrm{pH}$, amônia e nitrito, foram mensurados uma vez na semana através de kit colorimétrico (Alfakit ${ }^{\circledR}$ ) e obtidos os seguintes valores médios: oito unidades; $0,14 \pm 0,13 \mathrm{mg} \mathrm{L}^{-1}$ e $0,013 \pm 0,018 \mathrm{mg} \mathrm{L}^{-1}$. O oxigênio dissolvido, temperatura, pH (URBINATI et al. 2010), amônia e nitrito (PELLEGRIN et al. 2020) estão dentro do recomendado para a espécie.

Ao final do período experimental, os peixes foram mantidos em jejum de 24 horas e anestesiados com eugenol (50 $\mathrm{mg} \mathrm{L}^{-1}$ ) (GONÇALVES et al. 2008) para a biometria. Todos os peixes foram pesados individualmente em balança analítica de precisão (0,01g - Bel Marck M5202) e medidos com paquímetro digital (Starret 797B-8/200). Com isso, os parâmetros zootécnicos avaliados ao final do ensaio experimental foram: peso final $(\mathrm{PF})$ = peso do peixe inteiro; ganho em peso $(\mathrm{GP})$ = (peso final - peso inicial); comprimento total $(C T)=$ medida da porção anterior da cabeça até o final da nadadeira caudal; taxa de crescimento específico $(T C E)=[(\operatorname{Ln}$ peso final - Ln peso inicial $) /$ dias $] * 100$, onde $\operatorname{Ln}=$ logaritmo neperiano e conversão alimentar aparente $(C A A)=$ alimento consumido/ganho de peso. 
A avaliação do rendimento da carcaça $(R C)$ e de índices somáticos também ocorreu ao final do experimento e para tanto foram coletados três peixes por repetição (nove por tratamento), que foram abatidos com overdose de eugenol (100 $\mathrm{mg} \mathrm{L}^{-1}$ ) (GONÇALVES et al. 2008) e dissecados para a coleta de amostras. Os parâmetros foram estimados através das fórmulas: rendimento de carcaça $(R C)=$ peso do peixe sem as vísceras / peso total do peixe) * 100 ; índice hepatossomático $(\mathrm{IHS})=$ (peso do fígado / peso total do peixe) * 100; índice digestivo somático (IDS) $=\left(\right.$ peso do trato digestório / peso total do peixe) ${ }^{*} 100 \mathrm{e}$ o quociente intestinal $(\mathrm{QI})=$ (comprimento do trato / comprimento total do peixe) ${ }^{*} 100$.

Ao final do ensaio de alimentação foram coletados três peixes por unidade experimental (nove peixes por tratamento) que foram abatidos em água e gelo (1:1) e armazenados a $-18{ }^{\circ} \mathrm{C}$ até a realização das análises bromatológicas. Para realizar as análises os peixes foram pré-secos em estufa de recirculação de ar, em $60{ }^{\circ} \mathrm{C}$ durante um período de 24 horas, homogeneizados e analisados a matéria seca (MS), matéria mineral $(\mathrm{MM})$, proteína bruta (PB) e extrato etéreo (EE), a partir da metodologia adaptada de SILVA \& QUEIROZ (2009).

Os dados coletados foram submetidos ao teste de normalidade, para avaliar se os dados estão de acordo com os pressupostos estatísticos da normalidade, e submetidos à ANOVA de duas vias (fonte de fibra x níveis de inclusão) onde foram avaliadas a variação e a interação entre elas. Quando observada diferença significativa entre as médias, as mesmas foram submetidas ao teste de Tukey com $5 \%$ de probabilidade.

\section{RESULTADOS E DISCUSSÃO}

Não houve diferença significativa $(p>0,05)$ para as variáveis de desempenho em relação às fontes, porém houve diferença entre os níveis. Os níveis 10 e 13\% de FDN refletiram em resultados superiores para as variáveis de peso final, ganho de peso, TCE e comprimento total nos juvenis de pacu (Tabela 2).

Tabela 2. Dados de desempenho zootécnico de juvenis de pacu alimentados com níveis crescentes de Casca de Arroz e Casca de Soja, nos Níveis de 10, 13 e 15\% de FDN.

Table 2. Zootechnical performance data of juvenile pacu fed with increasing levels of rice husk and soybean husk at levels of 10,13 and $15 \%$ of NDF.

\begin{tabular}{lcccccc}
\hline Variáveis & & $\mathrm{PF}(\mathrm{g})$ & $\mathrm{GP}(\mathrm{g})$ & $\mathrm{TCE}\left(\% \mathrm{dia}^{-1}\right)$ & $\mathrm{CT}(\mathrm{cm})$ & CAA \\
\hline \multirow{\mathrm{Ft}}{*}{} & $\mathrm{CA}$ & $18,00 \pm 0,33$ & $11,71 \pm 0,33$ & $1,72 \pm 0,03$ & $9,65 \pm 0,60$ & $1,83 \pm 0,08$ \\
& $\mathrm{CS}$ & $17,82 \pm 0,33$ & $11,53 \pm 0,33$ & $1,70 \pm 0,03$ & $9,52 \pm 0,59$ & $1,88 \pm 0,12$ \\
\cline { 2 - 7 } & 10 & $18,45 \pm 0,42^{\mathrm{a}}$ & $12,16 \pm 0,42^{\mathrm{a}}$ & $1,76 \pm 0,04^{\mathrm{a}}$ & $9,70 \pm 0,77^{\mathrm{a}}$ & $1,77 \pm 0,10$ \\
$\mathrm{Ni}$ & 13 & $18,19 \pm 0,37^{\mathrm{a}}$ & $11,90 \pm 0,37^{\mathrm{a}}$ & $1,74 \pm 0,03^{\mathrm{a}}$ & $9,71 \pm 0,67^{\mathrm{a}}$ & $1,74 \pm 0,09$ \\
& 15 & $16,94 \pm 0,41^{\mathrm{b}}$ & $10,65 \pm 0,41^{\mathrm{b}}$ & $1,62 \pm 0,04^{\mathrm{b}}$ & $9,35 \pm 0,69^{\mathrm{b}}$ & $2,05 \pm 0,15$ \\
\hline $\mathrm{P}$ & & & & & \\
$\mathrm{Ft}$ & $\mathrm{NS}$ & $\mathrm{NS}$ & $\mathrm{NS}$ & $\mathrm{NS}$ & $\mathrm{NS}$ \\
$\mathrm{Ni}$ & $*$ & $*$ & $*$ & $*$ & $\mathrm{NS}$ \\
$\mathrm{FtxNi}$ & & $*$ & $*$ & $*$ & $*$ & $\mathrm{NS}$ \\
\hline $\mathrm{CA}$ & & $*$ & $*$
\end{tabular}

CA: Casca de arroz; CS: Casca de Soja; PF: Peso final; GP: Ganho em Peso; TCE: Taxa de Crescimento Especifico; CT: Comprimento total; CAA: conversão alimentar aparente; Ni: Nível de FDN; Ft: Fontes; NS: Não Significativo; ${ }^{*} \mathrm{P}<0,05$; Letras diferentes entre Ni ou Ft nas colunas, diferem estatisticamente pelo teste de Tukey $(P<0,05)$.

Em estudo já realizado com esta espécie, ao incluírem casca de soja ou polpa cítrica na dieta, FABREGAT et al. (2011b) observaram menores valores de peso final, TCE, comprimento final, consumo individual e CAA para os peixes alimentados com estas dietas, em comparação às dietas contendo farelo de soja ou farelo de girassol. Os altos níveis de fibra alimentar total (19,93 a $26,52 \%$ nas dietas contendo polpa cítrica) e fibra alimentar insolúvel (19,97\% na dieta contendo casca de soja), possivelmente contribuíram para estes resultados. Porém no estudo supracitado foi utilizado apenas um nível de inclusão da casca de soja $(26,4 \%)$, ao passo que no presente estudo foram utilizados três níveis de inclusão casca de soja na dieta dos peixes, sendo $15 \%$ o maior nível. Neste tratamento os peixes apresentaram menores valores para as variáveis de desempenho em comparação aos peixes alimentados com os níveis de 5 ou $10 \%$ de inclusão. Logo, sugere-se que níveis acima de $10 \%$ de casca de soja na dieta podem prejudicar 0 desempenho produtivo de juvenis de pacu. A casca de soja pode apresentar $64,33 \%$ de FDN (SILVA et al. 2004) e a casca de arroz $69,43 \%$ de FDN (ZAID \& GANIYAT 2009). A FDN corresponde à porção da fibra (celulose, hemicelulose e lignina) que é insolúvel em detergente neutro e grandes quantidades destes 
componentes nas dietas podem afetar negativamente o aproveitamento de outros nutrientes (MEURER \& HAYASHI 2003) e afetar o crescimento dos peixes, como foi observado no presente estudo.

Já a variável de CAA não diferiu $(p>0,05)$ entre os tratamentos (Tabela 2). A ingestão de fibras pode afetar o consumo de ração pelo aumento do bolo alimentar, aumentando a sensação de saciedade dos animais (RODRIGUES et al. 2010). No mesmo estudo, RODRIGUES et al. (2010) avaliaram os efeitos da inclusão de fibras na dieta de juvenis de pacu e observaram redução na CAA e no consumo de ração individual. Porém LANNA et al. (2004a), não observaram diferenças significativas ao avaliar a inclusão de fibras na dieta de juvenis de tilápia do Nilo (Oreochromis niloticus), concordando com os achados do presente estudo. Possivelmente as fontes e os níveis de inclusão testados no presente estudo não foram suficientes para afetar a CAA dos juvenis de pacu.

Foi possível observar efeito da interação entre as duas fontes para as variáveis de peso final, comprimento final, ganho de peso e TCE $(p<0,05)$ (Tabela 2). Os peixes alimentados com a casca de soja apresentaram melhores resultados para estas variáveis até o nível de $13 \%$ de FDN. Já, nas dietas contendo a casca de arroz, os peixes demonstraram resultados decrescentes conforme o aumento da inclusão deste ingrediente. Em um estudo realizado com a inclusão de níveis crescentes de casca de soja (4, 7 ou 10\%) na dieta de juvenis de jundiá, os autores não observaram diferença significativa para as variáveis de peso médio, comprimento total e ganho de peso diário, em comparação a outra fonte de fibra que foi a casca de algodão (PEDRON et al. 2008). Assim como no presente estudo, não foi observada diferença significativa para as variáveis de crescimento nos peixes alimentados com até 10\% de inclusão da casca de soja. Já para dietas contendo casca de arroz, HAYASHI et al. (2000) observaram menores valores para o comprimento final e ganho de peso em juvenis de tilápia do Nilo em comparação com os peixes alimentados com dietas contendo sabugo de milho e bagaço de cana hidrolisado. Segundo os autores, as grandes quantidades de lignina presentes na casca de arroz podem prejudicar a absorção de nutrientes e lesionar o trato digestivo dos peixes. Estes achados ajudam a reforçar que a casca de soja se caracteriza como uma melhor fonte de fibra para os peixes em comparação a casca de arroz.

Em relação ao rendimento de carcaça não foi observado efeito entre as fontes e interação entre as fontes e os níveis. Mas, foi observado melhor resultado para rendimento de carcaça na dieta com $10 \%$ de FDN, o que corresponde a $5 \%$ de inclusão de casca de soja ou $4 \%$ de inclusão de casca de arroz, em comparação os níveis de 13 ou 15\% de FDN nas dietas (Tabela 3). Este resultado pode estar relacionado com os fatores antinutricionais presentes nas fontes (casca de soja e arroz) como a lignina, hemicelulose e a celulose, que são componentes das fibras que podem afetar a digestibilidade de outros nutrientes. A casca de soja apresenta 3,21\% de lignina (SILVA et al. 2004) e a casca de arroz pode apresentar 25 a $30 \%$ de lignina (MANSARAY \& GHALY 1998). Dependendo da constituição das fibras e da quantidade de lignina e sílica presentes nela, podem resultar diferentes efeitos sobre 0 trato gastrointestinal dos peixes, dificultando a absorção de minerais e lesionando a parede do intestino e consequentemente afetando o seu desempenho (HAYASHI et al. 2000).

As variáveis de índice digestivo somático (IDS), quociente intestinal (QI) e o índice hepatossomático (IHS) não apresentaram diferença significativa $(P>0,05)$ entre as fontes e os níveis e nem efeito da interação (Tabela 3). Esses resultados estão de acordo com os observados para outras espécies como a piracanjuba (Brycon orbignyanus) (GARCIA et al. 1999), tilápia do Nilo (LANNA et al. 2004a) e jundiá (PEDRON et al. 2008). O índice hepatossomático está relacionado com o peso do fígado, órgão responsável pela regulação do metabolismo lipídico e energético (GARCIA et al. 1999). Já o índice digestivo somático e o quociente intestinal estão relacionados com a adaptação do sistema digestivo dos peixes ao alimento consumido (PEDRON et al. 2008). Diferentes espécies apresentam a capacidade de adaptar o seu intestino para aproveitar melhor diferentes tipos de alimentos.

RODRIGUES et al. (2011) avaliaram as adaptações do intestino de tilápia do Nilo e jundiá ao serem alimentados com diferentes fontes de fibra. Estes autores não observaram alterações em relação ao quociente intestinal nos peixes, porém foi observado um aumento da espessura muscular do intestino distal dos jundiás, como forma de adaptação da espécie ao alimento fibroso. Esta resposta foi diferente daquela expressada pela tilápia do Nilo, que também é uma espécie onívora, mas que apresentou melhor aproveitamento dos alimentos de origem vegetal. O pacu, assim como a tilápia do Nilo, apresenta hábito alimentar onívoro podendo aproveitar diferentes tipos de alimentos de origem vegetal. Com estes achados pode-se sugerir que as fontes e os níveis testados não foram suficientes para causar alterações no metabolismo lipídico e energético e no sistema digestivo dos juvenis de pacu. 
Tabela 3. Dados de Rendimento de Carcaça e Índices Somáticos de juvenis de pacu alimentados com níveis crescentes de Casca de Arroz e Casca de Soja, nos níveis de 10, 13 e 15\% de FDN.

Table 3. Carcass yield data and somatic indices of juvenile pacu fed increasing levels of rice husk and soybean husk, at levels of 10, 13 and $15 \%$ of NDF.

\begin{tabular}{llllll}
\hline Variáveis & & $\mathrm{RC}(\%)$ & IDS $(\%)$ & QI & IHS (\%) \\
\hline \multirow{F}{*}{$\mathrm{Ft}$} & $\mathrm{CA}$ & $88,27 \pm 0,19$ & $4,73 \pm 0,13$ & $0,72 \pm 0,02$ & $0,86 \pm 0,04$ \\
& $\mathrm{CS}$ & $87,70 \pm 0,27$ & $5,00 \pm 0,11$ & $0,70 \pm 0,02$ & $0,87 \pm 0,04$ \\
\cline { 2 - 6 } $\mathrm{Ni}$ & 10 & $88,63 \pm 0,20^{\mathrm{a}}$ & $4,81 \pm 0,18$ & $0,70 \pm 0,03$ & $0,87 \pm 0,05$ \\
& 13 & $87,36 \pm 0,37^{\mathrm{b}}$ & $5,01 \pm 0,14$ & $0,71 \pm 0,02$ & $0,91 \pm 0,06$ \\
$\mathrm{P}$ & 15 & $87,97 \pm 0,21^{\mathrm{ab}}$ & $4,78 \pm 0,12$ & $0,72 \pm 0,02$ & $0,82 \pm 0,03$ \\
$\mathrm{Ft}$ & & & & \\
$\mathrm{Ni}$ & & $\mathrm{NS}$ & $\mathrm{NS}$ & $\mathrm{NS}$ & $\mathrm{NS}$ \\
$\mathrm{FtxNi}$ & & $\mathrm{NS}$ & $\mathrm{NS}$ & $\mathrm{NS}$ \\
\hline
\end{tabular}

CA: Casca de Arroz; CS: Casca de Soja; RC: Rendimento de Carcaça; IDS: Índice Digestivo Somático; QI: Quociente Intestinal; IHS: Índice Hepatossomático; Ni: Nível de FDN; Ft: Fontes; FtxNi: Interação entre Fonte x Nível; NS: Não Significativo; ${ }^{*} \mathrm{P}<0,05$; Letras diferentes entre $\mathrm{Ni}$ ou $\mathrm{Ft}$ nas colunas, diferem estatisticamente pelo teste de Tukey $(P<0,05)$.

Em relação à composição centesimal, não foram observadas diferenças significativas $(p>0,05)$ entre os tratamentos e nem interação entre as variáveis para os teores de matéria seca total (MST), matéria mineral (MM), proteína bruta (PB) e extrato etéreo (EE) dos peixes inteiros (Tabela 4). As fibras podem afetar a qualidade do alimento e a absorção de nutrientes no epitélio intestinal (HANSEN \& STOREBAKKEN 2007). Segundo estes autores a celulose aumenta a durabilidade e reduz a expansão dos pellets, além de diminuir a absorção do sódio por juvenis de truta arco-íris (Oncorhynchus mykiss), devido ao potencial de ligação que alguns minerais catiônicos (como o sódio) têm pelos grupos hidroxila que a celulose apresenta.

Tabela 4. Composição Centesimal da Carcaça dos juvenis de pacu alimentados com níveis crescentes de Casca de Arroz e Casca de Soja, nos níveis de 10, 13 e 15\% de inclusão de FDN, apresentados na matéria parcialmente seca.

Table 4. Centesimal carcass composition of pacu juveniles fed with increasing levels of rice husk and soybean husk, at levels of 10, 13 and 15\% of NDF, presented in partially dry matter.

\begin{tabular}{llllll}
\hline Variáveis & & MST $(\%)$ & MM (\%) & PB (\%) & EE (\%) \\
\hline \multirow{Ft}{Ft}{} & $\mathrm{CA}$ & $25,57 \pm 0,23$ & $4,10 \pm 0,05$ & $12,74 \pm 0,51$ & $5,66 \pm 0,15$ \\
& $\mathrm{CS}$ & $25,19 \pm 0,16$ & $4,01 \pm 0,04$ & $12,81 \pm 0,56$ & $5,92 \pm 0,24$ \\
\cline { 2 - 6 } $\mathrm{Ni}$ & 10 & $25,34 \pm 0,13$ & $4,04 \pm 0,07$ & $12,90 \pm 0,76$ & $5,70 \pm 0,19$ \\
& 13 & $25,28 \pm 0,32$ & $4,08 \pm 0,05$ & $13,17 \pm 0,42$ & $5,58 \pm 0,24$ \\
$\mathrm{P}$ & 15 & $25,51 \pm 0,27$ & $4,03 \pm 0,07$ & $12,25 \pm 0,71$ & $6,10 \pm 0,29$ \\
$\mathrm{Ft}$ & $\mathrm{NS}$ & $\mathrm{NS}$ & $\mathrm{NS}$ & $\mathrm{NS}$ \\
$\mathrm{Ni}$ & $\mathrm{NS}$ & $\mathrm{NS}$ & $\mathrm{NS}$ & $\mathrm{NS}$ \\
$\mathrm{FtxNi}$ & $\mathrm{NS}$ & $\mathrm{NS}$ & $\mathrm{NS}$ & $\mathrm{NS}$ \\
\hline
\end{tabular}

CA: Casca de Arroz; CS: Casca de Soja; MST: Matéria Seca Total; MM: Matéria Mineral; PB: Proteína Bruta; EE: Extrato Etéreo. Ni: Nível de FND; Ft: Fontes; FtxNi: Interação entre Fonte x Nível; NS: Não Significativo. ${ }^{*}<<0,05$; Letras diferentes entre Ni ou Ft nas colunas, diferem estatisticamente pelo teste de Tukey $(P<0,05)$.

No estudo de PEDRON et al. (2008), os autores observaram maiores valores para matéria mineral, devido à maior quantidade de lignina presente na casca de algodão, que tem maior afinidade com os íons metálicos, podendo afetar a absorção e retenção de minerais, e o extrato etéreo, pela maior quantidade de substâncias pécticas presentes na casca de soja, podendo aumentar a produção de ácidos graxos voláteis no intestino nos juvenis de jundiá alimentados com a casca de soja em comparação aos alimentados com casca de algodão. LANNA et al. (2004b) observaram também redução da digestibilidade aparente da matéria seca, proteína bruta e extrato etéreo em juvenis de tilápia do Nilo conforme aumentou a fibra bruta na dieta, utilizando a celulose como fonte de fibra, situação que pode afetar a deposição de nutrientes pelos 
peixes.

Contudo, no presente trabalho, não foram observadas diferenças para nenhuma das variáveis centesimais, assim como, GARCIA et al. (1999) não observaram diferenças significativas sobre a matéria mineral, proteína bruta e extrato etéreo em juvenis de piracanjuba. Desta forma, as fontes e os níveis de inclusão testados no presente trabalho não foram suficientes para afetar a deposição destes nutrientes nos juvenis, mesmo afetando o rendimento de carcaça. Possivelmente devido à característica onívora do pacu, que conseguiu aproveitar melhor os nutrientes da dieta, sem afetar a absorção e deposição de outros nutrientes.

\section{CONCLUSÃO}

A inclusão de até $10 \%$ de casca de soja ou $8 \%$ de casca de arroz ou até o nível de $13 \%$ de FDN na dieta de juvenis de pacu não compromete o crescimento, a conversão alimentar, os parâmetros somáticos e a composição centesimal dos peixes inteiros, embora tenha diminuído o rendimento de carcaça dos peixes. Em contrapartida, o nível de 15\% de FDN prejudica o desempenho dos peixes.

\section{REFERÊNCIAS}

BOSCOLO WR et al. 2011. Nutrição de peixes nativos. Revista Brasileira de Zootecnia 40: 145-154.

FABREGAT TEHP et al. 2011a. Efeito da fonte de fibra no trânsito gastrointestinal e digestibilidade do pacu (Piaractus mesopotamicus). Revista Acadêmica: Ciências Agrárias e Ambientais 8: 279-287.

FABREGAT TEHP et al. 2011b. Fontes de fibra na alimentação do pacu: desempenho, composição corporal e morfometria intestinal. Arquivo Brasileiro de Medicina Veterinária e Zootecnia 63: 1533-1540.

GARCIA JE et al. 1999. Utilização da fibra bruta na nutrição da piracanjuba (Brycon orbignianus). Acta Scientiarium Animal Sciences 21: 725-731.

GONÇALVES AFN et al. 2008. Mentol e eugenol como substitutos da benzocaína na indução anestésica de juvenis de pacu. Acta Scientiarum Animal Sciences 30: 339-344.

GOULART FR et al. 2018. Effect of dietary fiber concentrates on growth performance, gut morphology and hepatic metabolic intermediates in jundiá (Rhamdia quelen). Arquivo Brasileiro de Medicina Veterinária e Zootecnia 70: 16331640.

HANSEN JØ \& STOREBAKKEN T 2007. Effects of dietary cellulose level on pellet quality and nutrient digestibilities in rainbow trout (Oncorhynchus mykiss). Aquaculture 272: 458-465.

HAYASHI C et al. 2000. Fontes de fibra bruta em dietas de alevinos de tilápia-do-Nilo (Oreochromis niloticus). Acta Scientiarium Animal Sciences 22: 689-694.

IBGE. 2019. Disponível em: https://sidra.ibge.gov.br/tabela/3940. Acesso em: 14 fev. 2020.

LANNA EAT et al. 2004a. Fibra bruta e óleo em dietas práticas para alevinos de tilápia do Nilo (Oreochromis niloticus). Revista Brasileira de Zootecnia 33: 2177-2185.

LANNA EAT et al. 2004b. Digestibilidade aparente e trânsito gastrintestinal em tilápia do Nilo (Oreochromis niloticus), em função da fibra bruta da dieta. Revista Brasileira de Zootecnia 33: 2186-2192.

MANSARAY KG \& GHALY AE. 1998. Thermal degradation of rice husks in nitrogen atmosphere. Bioresource Technology 65:13-20.

MEURER F \& HAYASHI C. 2003. Polissacarídeos não amiláceos na nutrição de peixes - Revisão. Arquivo de Ciências Veterinárias e Zoologia 6:127-138.

MEYER G et al. 2004. A importância da quantidade de energia na ração de peixes. Panorama da Aquicultura 14: 53-57.

MIRGHAED AT et al. 2018. The effects singular or combined administration of fermentable fiber and probiotic on mucosal immune parameters, digestive enzyme activity, gut microbiota and growth performance of Caspian white fish (Rutilus frisii kutum) fingerlings. Fish and Shellfish Immunology 77: 194-199.

MONTAGNE $L$ et al. 2003. A review of interactions between dietary fiber and the intestinal mucosa, and their consequences on digestive health in young non-ruminant animals. Animal Feed Science and Technology 108: 95-117.

PEDRON FA et al. 2008. Cultivo de jundiás alimentados com dietas com casca de soja ou de algodão. Pesquisa Agropecuária Brasileira 43: 93-98.

PELLEGRIN L et al. 2020. Alkaline water improves the growth and antioxidant responses of pacu juveniles (Piaractus mesopotamicus). Aquaculture 519: 734713.

RODRIGUES APO et al. 2011. Different utilization of plant sources by the omnivores jundiá catfish (Rhamdia quelen) and Nile tilapia (Oreochromis niloticus). Aquaculture Nutrition 18: 65-72.

RODRIGUES LA et al. 2010. Desempenho produtivo, composição corporal e parâmetros fisiológicos de pacu alimentado com níveis crescentes de fibra. Pesquisa Agropecuária Brasileira 45: 897-902.

ROSTAGNO HS et al. 2005. Tabelas Brasileiras para Aves e Suínos. Composição de Alimentos e Exigências Nutricionais. 2.ed. Viçosa: Universidade Federal de Viçosa.

SILVA DJ \& QUEIROZ AC. 2009. Análise de alimentos: métodos químicos e biológicos. 3.ed. Viçosa: Universidade Federal de Viçosa.

SILVA DC et al. 2004. Digestibilidade in vitro e degradabilidade in situ da casca do grão de soja, resíduo de soja e casca de algodão. Acta Scientarium Animal Sciences 26: 501-506.

Rev. Ciênc. Agrovet., Lages, SC, Brasil (ISSN 2238-1171) 
URBINATI EC et al. 2010. Pacu (Piaractus mesopotamicus). In: BALDISSEROTTO B \& GOMES LC (2 Ed.). Espécies nativas para piscicultura no Brasil. Santa Maria: UFSM. p. 205-244.

ZAID AA \& GANIYAT O. 2009. Comparative utilization of biodegraded and undegraded rice husk in Clarias gariepinus diet. African Journal of Biotechnology 8: 1358-1362. 